\title{
DO RUBRO-NEGRO AO NEUTRO DA FIFA: UMA ANÁLISE DAS TRANSFORMAÇÕES DOS ESTÁDIOS-SEDE DA COPA DO MUNDO DE 2014
}

\author{
FROM "RUBRO-NEGRO" TO FIFA'S NEUTRALITY: AN ANALYSIS OF CHANGES \\ IN 2014 WORLD CUP STADIUMS
}

\author{
DEL ROJINEGRO A LA NEUTRALIDAD DE LA FIFA: UN ANÁLISIS DE LAS \\ TRANSFORMACIONES DE LOS ESTADIOS DEL MUNDIAL DE FÚTBOL DE 2014
}

\author{
Emília Amélia Pinto Costa Rodrigues*, Andreia Juliane Drula*, Simone Rechia*
}

\section{Palavras chave:}

Futebol.

Atividades de lazer.

Área urbana.
Resumo: Este artigo teve o objetivo de analisar alguns aspectos referentes aos estádios das cidades-sede da Região Sul do Brasil, verificando o que influenciou as (re)criações de suas estruturas, quais as suas principais características e quais as consequências de tais transformações para as experiências no âmbito do esporte e do lazer. Foram estudados os estádios-sede: Joaquim Américo Guimarães, em Curitiba, e José Pinheiro Borda, 0 Beira-Rio, em Porto Alegre. Mudanças marcantes ocorreram nos estádios. 0 chamado "caldeirão" do Rubro-Negro, marcado pela cor vermelha, passou, após as reformas, a ter características idênticas às dos demais estádios mundiais de futebol, com predomínio de cores neutras. Também houve mudanças em relação às normas e à forma de assistir ao jogo, gerando distanciamento entre o jogador e o torcedor, com o intuito de controlar as emoções e expressões corporais dos torcedores, transformando os estádios em arenas multifuncionais.

Keywords: Soccer. Leisure activities. Urban area.
Abstract: This article analyzed some aspects related to stadiums in the host cities of southern Brazil, verifying what influenced the (re)creations of their structures and their main characteristics and consequences of such transformations to sports and leisure experiences. The stadiums of southern Brazil studied were: Joaquim Américo Guimarães, in Curitiba, and José Pinheiro Borda, Beira-Rio, in Porto Alegre. Significant changes occurred in the stadiums. The so-called "cauldron" of the Rubro-Negro (Red-Black), marked by its red color, gained characteristics similar to those of other world football stadiums after the reforms, with a predominance of neutral colors. There were also changes in the rules and way of watching matches, resulting in distance between players and fans in order to control the latter's emotions and expressions and turn stadiums into multifunctional arenas.
Palabras clave:

Fútbol.

Actividades de ocio. Área urbana.
Resumen: Este artículo tuvo el objetivo de analizar algunos aspectos referentes a los estadios de las ciudades que fueron sede en la región sur de Brasil, verificando lo que influenció las (re)creaciones de sus estructuras, cuáles son sus principales características y las consecuencias de esas transformaciones para las experiencias en el ámbito del deporte y del ocio. Se estudiaron los estadios sede: Joaquim Américo Guimarães (Curitiba) y José Pinheiro Borda (Porto Alegre). Los cambios más destacados ocurrieron en los estadios. El conocido como "caldeirão" del Rojinegro, identificado por su color rojo, pasó, después de las reformas, a tener características idénticas a las de los demás estadios mundiales de fútbol, con predominio de colores neutros. También hubo cambios en relación a las normas y a la forma de asistir al juego, generando distancia entre el jugador y el hincha, con el propósito de controlar las emociones y expresiones corporales de los hinchas, transformando los estadios en arenas multifuncionales.
*Universidade Federal do Paraná. Curitiba, PR, Brasil. Email: milapcosta@ hotmail.com deia.drula@gmail.com, simone@ufpr.com.br>

Recebido em: 30-03-2017 Aprovado em: 27-09-2017

DOI: http://dx.doi.org/10.22456/1982-8918.72230 (c) (1) (8) Licence 


\section{INTRODUÇÃOO}

A vinda da Copa do Mundo de Futebol remete a muitas transformações das cidades no que diz respeito à infraestrutura, mobilidade urbana, segurança e aos estádios. A cidade passa a ser tratada como negócio e/ou mercadoria, entendendo que, por meio da mercantilização, há uma promoção do espaço citadino (seja no âmbito da economia, do turismo e/ou da promoção de sua imagem). Percebe-se também uma preocupação com a estética em detrimento da ética.

Para Harvey (2012, p. 35), nas grandes transformações das cidades modernas, a "[...] estética triunfou sobre a ética como foco primário de preocupação intelectual e social, as imagens dominaram as narrativas, a efemeridade e a fragmentação assumiram procedência sobre verdades eternas". Ou seja, na lógica do capital, há uma substituição dos valores éticos por imagens e espaços efêmeros (HARVEY, 2012), e isso pode comprometer a sociedade em diversas esferas, como a educacional, econômica, da saúde, entre outras, além de gerar falta de diálogo com a comunidade, favorecendo os desvios de recursos financeiros.

A cidade-sede de um megaevento esportivo busca um espaço na globalização, seja ela: 1. Como fábula: à qual são atribuídas características positivas, como democratização e a ascensão econômica para todos; 2 . Como ela é: pautada no consumismo e na perversidade da desigualdade; 3 . 0 que ela pode ser: isto é, outra globalização que proporcione o real acesso à informação, discussão e sua difusão, de formação de redes sociais, entre outros atributos, todos com vistas à emancipação humana (SANTOS, 2006).

Nesse caso, entende-se que os megaeventos esportivos, a exemplo da Copa do Mundo, inseridos nos processos de globalização, podem agregar sentidos e significados aos cidadãos a partir da reurbanização e qualificação dos espaços da cidade no tocante ao acesso, à segurança, à acessibilidade e às melhorias nos espaços de lazer e esporte. Mas também podem segregar a partir das desapropriações dos espaços onde vivem determinadas comunidades e também pelas interferências na cultura local, já que a FIFA ${ }^{1}$ tem normatizações válidas para todos os países, independentemente de suas características.

Percebe-se que as mudanças que ocorrem nas cidades e em suas estruturas por conta de megaeventos esportivos, aqui, especificamente, a Copa do Mundo, reforçam uma ideia central da globalização, pois, de acordo com Santos (2006, p. 143), a globalização agrava a heterogeneidade, dando-lhe um caráter apenas estrutural. Ou seja, a globalização estabelece uma ordem global sobre uma ordem local. Tal lógica desconsidera singularidades de determinados meios urbanos e seus espaços, regulando estruturas materiais para tornálas uniformizadas, muitas vezes sem sentido ou significado para os sujeitos que vivem em cidades impactadas pela ordem global.

Uma das estruturas materiais alteradas por esse princípio são os estádios mundiais de futebol, por essa razão, tais ambientes tornam-se objetos de estudos importantes, despertando 0 interesse de diversas áreas pela temática, como a Educação Física, Geografia, História, Arquitetura, Sociologia, dentre outras. Nesse sentido, nosso interesse é desvendar aspectos referentes a tais alterações e seus impactos nas experiências no

1 Fédération Internationale de Football Association, instituição que rege o megaevento esportivo Copa do Mundo de Futebol. 
âmbito do lazer no que tange às diferentes formas de uso e apropriação de tais ambientes (ARAÚJO, 2008; CAMPOS; AMARAL, 2013; CERETO, 2003; CRUZ, 2005).

Uma das principais características dessas transformações foi adaptar os estádios para o uso multifuncional, no intuito de que esses espaços passassem a ter mais funções além de comportar torcedores para uma partida de futebol. Nessa direção, até a terminologia de "estádio" sofre alteração, pois esses lugares foram, a partir de então, denominados "arenas". Dentro "deste conceito multifuncional passa a ser a âncora de um grande complexo centrado no entretenimento; forja-se então o conceito arquitetônico de 'estado da arte' no setor esportivo" (ARAÚJO, 2008, p. 555).

As transformações foram especificamente modificações físicas: modernização de acesso nas entradas do espaço; comodidade nas arquibancadas, as quais passam a adotar cadeiras do tipo retráteis; telões LED; novos espaços para alimentação; grande proximidade entre a torcida e o gramado; tetos retráteis; e até mesmo na estética, quanto à arquitetura e às cores que constituem o estádio (DRULA, 2015). Contudo, mesmo que aconteçam no plano físico-estrutural, as transformações podem incidir nas formas de apropriação dos sujeitos, pois agora exigem deles uma modificação de comportamento, via normativas regulatórias, alterando a cultura local estabelecida naquele espaço.

As Copas do Mundo FIFA mais recentes têm se configurado como um dos maiores eventos esportivos que existem, requerendo, aos países elegidos como sede, mudanças em diferentes setores do meio social para comportar essa competição internacional. Palco das principais atrações desse campeonato, os estádios participantes devem aderir aos ditos "padrões" que a FIFA estabelece, sendo que:

[...] as exigências gerais para os estádios da Copa do Mundo FIFA não diferem daquelas para partidas internacionais normais ou de primeira divisão - mas a diferença em escala de requisitos é enorme. As exigências para um estádio da Copa do Mundo FIFA são grandes [...] (FIFA, 2011, p. 5).

De acordo com a FIFA (2011), as transformações dos estádios a partir de seus moldes devem proporcionar a inexistência de pontos cegos das arquibancadas com o campo de jogo, bem como melhorias na segurança, estacionamentos no estádio, área de jogo, locais de comodidade nas arquibancadas para espectadores, hospitalidade, área de mídia, iluminação e energia, comunicação e criação de áreas adicionais e de instalações temporárias para as partidas.

Essa configuração estrutural é pensada de forma universal. Ao analisar os estádios a partir do padrão FIFA, identifica-se a repetição de modelos, muitas vezes interferindo na cultura local de um determinado time de futebol, entre outros grandes problemas de segregação global. Nesse caso, entende-se que as novas formas de uso podem "ocasionar a apropriação de uns e a desapropriação de outros" (RECHIA; SILVA, 2014, p. 211) ao excluir determinadas culturas já arraigadas e ao gerar formas diferenciadas de apropriação em função de outras práticas sociais oferecidas pelos ambientes (re)criados.

Nesse sentido, o presente artigo pretende responder ao seguinte questionamento: as novas formas dos estádios interferem no sentido e significado do espaço? Sendo assim, o objetivo do texto é descrever os estádios das cidades-sede da Região Sul do Brasil, verificando o que influenciou as (re)criações de suas estruturas, quais as principais características e as atividades relacionadas ao lazer e esporte. 


\section{METODOLOGIA}

Este artigo é um recorte da tese intitulada Os espaços das cidades e os megaeventos esportivos: uma análise da Copa do Mundo de Futebol 2014 na Região Sul do Brasil. É uma pesquisa descritiva e exploratória de campo, tendo a finalidade de observar, registrar e analisar fenômenos atuais, conforme Marconi e Lakatos (2011).

Os estádios delimitados para o estudo foram os estádios-sede da Copa do Mundo de 2014, da Região Sul do Brasil (Curitiba/PR e Porto Alegre/RS). No caso, o estádio Joaquim Américo Guimarães, em Curitiba, e o Estádio José Pinheiro Borda, o Beira-Rio, em Porto Alegre.

Como instrumento, foi utilizado um protocolo de observação, que permite o envolvimento do pesquisador com o cenário do estudo. De acordo com Marconi e Lakatos (2011), a observação permite 0 uso dos sentidos para estudar o ambiente, bem como comportamentos individuais e grupais, a linguagem não verbal, a sequência e a temporalidade dos eventos. Nesse caso, foi utilizado como base um roteiro desenvolvido pelo Grupo de Estudos e Pesquisas em Lazer, Espaço e Cidade (GEPLEC), da Universidade Federal do Paraná, que procura identificar as condições dos espaços e equipamentos e suas respectivas formas de uso. O roteiro de observação contemplou questões sobre estado de conservação, estrutura, iluminação, limpeza, localização, ponto de transporte público, áreas para vivências de esporte e lazer, entre outros aspectos.

A primeira etapa da coleta de dados ocorreu no período que antecedia a Copa do Mundo de 2014. O roteiro de observação foi preenchido no período de março a junho de 2014 e reaplicado um ano após a realização do mundial, em junho e julho de 2015. Ao todo, foram feitas 11 visitas ao Estádio Joaquim Américo, em Curitiba, e dez visitas ao Estádio Beira-Rio, em Porto Alegre.

Este estudo foi aprovado pelo Comitê de Ética em Pesquisa com Seres Humanos do Hospital do Trabalhador/SES/PR, parecer n 607.680, conforme a resolução no 466/12 do Conselho Nacional de Saúde (BRASIL, 2012a).

\section{CARACTERIZANDO OS ESTÁDIOS-SEDE DA COPA DO MUNDO DE 2014 DA REGIÃO SUL DO BRASIL}

Os dois estádios, tanto o de Curitiba como o de Porto Alegre, são privados e passaram por grandes mudanças. Suas respectivas estruturas foram modificadas para atender às normas da FIFA.

O Estádio Joaquim Américo Guimarães, localizado no bairro Água Verde, na cidade de Curitiba, foi fundado em 1913. Na sua primeira construção, comportava mil pessoas (DRULA, 2015). Em 1997, o estádio passou por uma grande reforma e foi reinaugurado em 1999 com um novo modelo de estádio para o cenário brasileiro, com capacidade para 32.864 pessoas. Com a vinda da Copa do Mundo para o Brasil, o estádio teve que passar novamente por reformas para atender às exigências da FIFA. Conforme o Ministério do Esporte, a reforma do estádio de Curitiba custou aproximadamente $\mathrm{R} \$ 391$ milhões, e o local passou a ter capacidade para 43 mil espectadores (BRASIL, 2012b). 
O Estádio Beira-Rio, localizado no bairro Praia de Belas, em Porto Alegre, foi inaugurado em 1969, tendo capacidade para 100 mil torcedores. Também em virtude da Copa do Mundo de 2014 o Beira-Rio passou por uma grande reforma para atender às exigências da FIFA. A reforma do Beira-Rio foi considerada a mais barata reforma de um estádio brasileiro, com custo de $\mathrm{R} \$ 366$ milhões, de acordo com o portal da transparência (BRASIL, 2014). Atualmente 0 Beira-Rio tem capacidade para 50 mil pessoas.

\section{ESTÁDIO JOAQUIM AMÉRICO E BEIRA-RIO: UMA ANÁLISE EM TEMPOS DE MEGAEVENTOS ESPORTIVOS}

Tanto o Joaquim Américo como o Beira-Rio são estádios que transformaram suas estruturas para atender às normas da FIFA, as quais são requisitos obrigatórios a serem atendidos e requalificados a partir das recomendações técnicas para receber o megaevento esportivo. ${ }^{2}$ Percebe-se nos documentos regulatórios da FIFA que a ideia é tornar semelhantes todos os estádios de futebol quanto a requisitos como neutralidade das cores, segurança, acessibilidade, espaços de lazer, praças de alimentação, entre outros.

Para Harvey (2012, p. 22), a modernidade "não apenas envolve uma implacável ruptura com todas e quaisquer condições históricas precedentes como é caracterizada por um interminável processo de rupturas e fragmentações internas inerentes". Percebe-se assim que as mudanças impostas pela FIFA ocorridas nos estádios romperam com um modelo estrutural e de formas de uso já estabelecido localmente. Assim, rompe-se com marcas identitárias estabelecidas para os "estádios de cidades" para ressignificá-los como "estádios-sede da Copa do Mundo", independentemente do país-sede, com ênfase à identidade "neutra".

Tais inovações arquitetônicas impostas muitas vezes ocorrem de forma indesejada e ocasionam também mudanças culturais, principalmente por não haver um diálogo entre os sujeitos que já utilizavam os espaços e as instituições responsáveis pelas modificações.

Um dos fatores que mais chamou atenção dos torcedores entrevistados foi a mudança das cores tradicionais dos estádios. A cor cinza remete ao neutro e, segundo os documentos oficiais, possibilita a valorização das cores das camisas dos clubes de futebol, proprietários dos estádios. Outra explicação para a cor neutra é que, como se almejam estádios multifuncionais, optou-se por não fazer identificações com a cor do time, e assim poder agregar outras ações voltadas ao espetáculo (RODRIGUES, 2016; DRULA; 2015).

Drula (2015, p. 53), ao pesquisar as transformações do Estádio Joaquim Américo, entrevistou um historiador do referido estádio e foi informado de que a mudança das cores foi proposital, pois a diretoria acreditava que as cores neutras seriam indiferentes, para eles: "[...] se o torcedor adversário for num show não vai quebrar a cadeira porque ela é cinza, e não vermelha [...]. Todo mundo sabe que é um estádio do Atlético [...] nesse sentido, perde somente um pouco da identidade".

No entanto, a mesma autora entrevistou também um frequentador do estádio, questionando-o em relação à mudança de cores e perda da identidade.

As chapas cinza que compõem o estádio não têm nada a ver, o estádio tem dono, e a identidade tinha que ter sido mantida. Poderiam botar as cadeiras vermelhas,

2 Para a Copa do Mundo de 2014, foram seguidas as recomendações para transformações a partir do estipulado no manual da FIFA. Estádios de Futebol: recomendações e requisitos técnicos. 5. ed. Zurique, Suiça: FIFA, 2011. 
mas já tem muito estádio que tem cadeira vermelha, então poderia ter sido colocada preta, ou colorido, achei que ficou muito frio e não representa o que é a torcida do CAP [...]. Eles deveriam ter deixado a identidade do clube mais nítida, e não fizeram, cinza, frio, que não tem nada a ver com o CAP, com a história do time e da torcida (DRULA, 2015, p. 52).

Há uma forte relação entre as cores do time e a identidade da torcida. Por mais simbólica que seja a estética do lugar, os laços estabelecidos com os elementos nas cores rubro-negras, seja nas cadeiras, na fachada, dentre outros, são sobremaneira especiais para o torcedor atleticano porque criam laços de identidade com o lugar e com o clube, e quando alteradas podem interferir nas formas de apropriação dos sujeitos (DRULA, 2015, p. 52-53).

Certeau (1995, p. 58) alerta sobre a falta de inocência que os procedimentos estratégicos carregam em si, já que "seus objetivos dependem de uma organização política [...], cujo objetivo é 'ocultar o que ele pretende mostrar'", pois, muitas vezes, camuflar os elementos mais óbvios de um espaço e, aqui especificamente, de espaços predefinidos para a experiência do futebol é uma possibilidade de abrir portas para outras experiências, como as multifuncionais vinculadas a outros interesses culturais no âmbito do lazer e entretenimento.

Assim, a partir da tradição clubística que o Brasil ostenta em seus estádios de futebol, por mais neutros (ou cinza) que as instituições tentem deixar esses espaços, a marca identitária de determinado time prevalecerá, principalmente quando se tratar de estádios privados. A título de exemplo, as imagens a seguir revelam esses aspectos. $O$ estádio em que antes a cor vermelha predominava passou a ser totalmente cinza (Figura 1).

Figura 1 - Reforma do estádio do Atlético: antes e depois

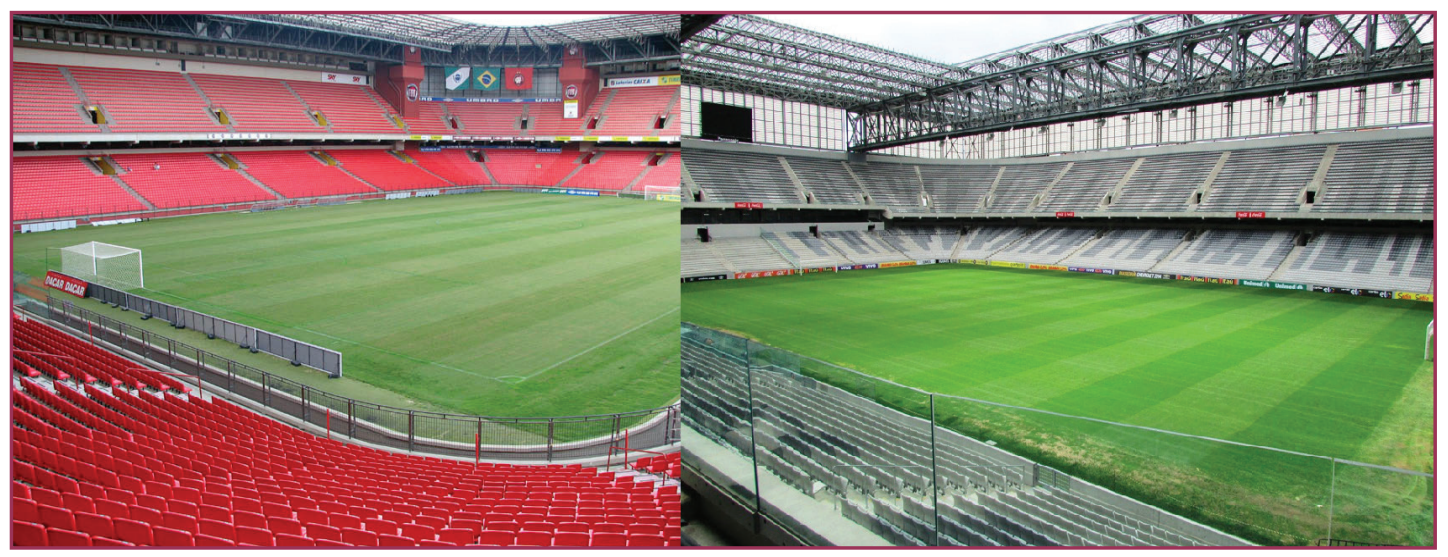

Fonte: ANIBAL (2011); Arquivo Pessoal (2017).

Em Porto Alegre, embora a cor branca predomine no lado externo do estádio, o vermelho ainda prevaleceu na parte interna. Conforme Gastal (2009), as transformações impostas para os estádios de futebol remetem a uma re-elitização no esporte, como foi percebido nos resultados da reforma do Beira-Rio.

Na Figura 2, a seguir, está demonstrado o interior do estádio Beira-Rio, antes e depois da reforma. 
Figura 2 - Estádio Beira-Rio, antes e depois da Copa

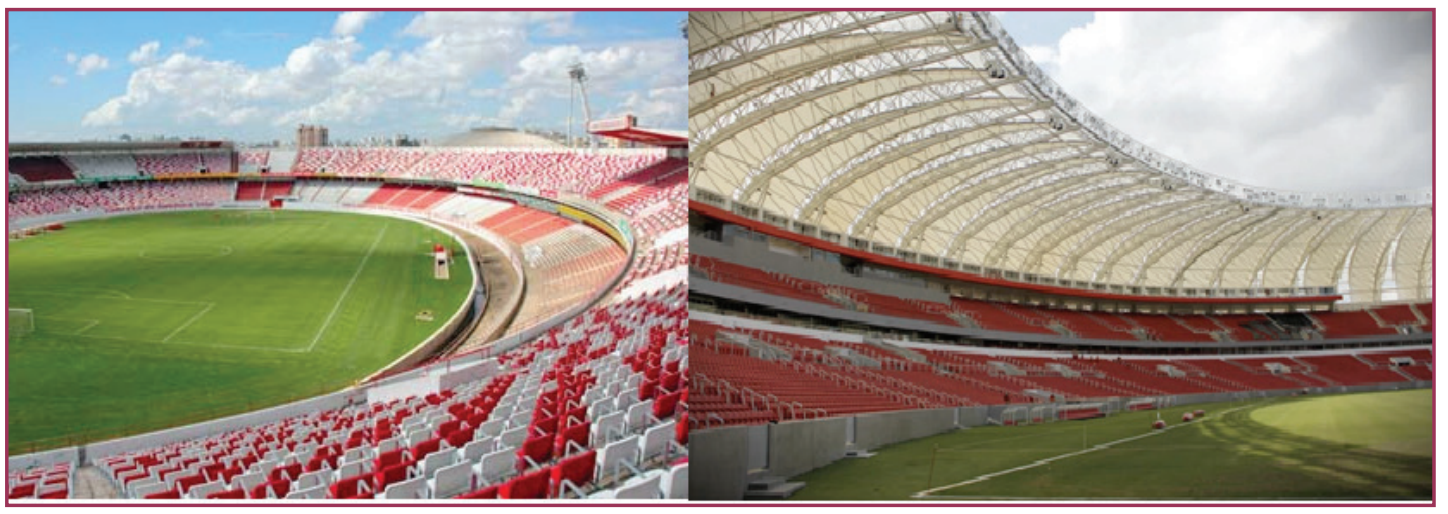

Fonte: ANIBAL (2011); GUICHARD (2014).

De acordo com Gastal (2009), as transformações ocorridas no estádio por conta da Copa interferiram no espetáculo que a torcida tinha anteriormente, visto que agora não se pode assistir aos jogos em pé e segurando instrumentos.

Berzagui (2014, p. 49), que realizou um estudo dos novos estádios de Porto Alegre, ressalta que a maneira de agir dentro dos estádios estava anteriormente mais relacionada ao "extravasamento emocional do que os agora aplicados códigos de conduta e de contenção emocional ou de comportamento 'socialmente correto"'.

\section{AS PRINCIPAIS MUDANÇAS NOS ESTÁDIOS: SENTIDOS E SIGNIFICADOS DO ESPAÇO}

Em primeiro lugar, é necessário compreender o conceito de cultura para entender de que forma as transformações nos estádios-sede interferiram na cultura local dos torcedores e frequentadores desses espaços. Alves (2004, p. 59) discute o conceito de cultura a partir da análise dos seguintes estudiosos: Canclini (1997); Canevacci (1993); Featherstone (1995) e Maffesoli (1987), ressaltando que:

A partir de análises teóricas diferenciadas, afirmam que a cultura nestes novos tempos não pode conviver com a ideia do todo formatado por partes, mas sim numa perspectiva de rede, este conjunto inorganizado e, no entanto, sólido, invisível, que serve de ossatura a qualquer outro conjunto, seja ele qual for (ALVES,2004, p. 59).

Sendo assim, Alves (2004, p. 59) ainda destaca que "[...] o tempo de fluxo de informações, conhecimentos e imagens são constituídos de formas interdependentes. Essas características introduzem novas estruturações sociais no que tange às relações entre os indivíduos e às novas formas de agrupamentos". A autora complementa que essas relações também são estabelecidas com as novas territorialidades ou a desterritorialidade, "provando diferentes maneiras de se situar nos tempos e espaços culturais".

As "culturas" podem ser passadas de geração a geração, e assim ocorrem transformações que vão se incorporando ao longo do tempo. Com a reforma dos estádios para a realização dos jogos, houve algumas mudanças e interrupções nas formas de apropriação desses espaços.

De acordo com o Sindicato da Arquitetura e da Engenharia (2010) apud Branski et al. (2013), a utilização dos estádios da Copa do Mundo seria diversificada: 
- Estádio Joaquim Américo, sede do tradicional Clube Atlético Paranaense: projetado para ser um espaço múltiplo, abrigando business center, praça de alimentação e centro comercial.

- Estádio Beira-Rio, sede do popular time Internacional de Porto Alegre: reformado para receber espetáculos e convenções, além da construção de um hotel anexo.

Esses projetos não foram concluídos antes da realização da Copa, mas os estádios vêm passando por transformações. Um fator importante a destacar é que, por serem privados, esses estádios possuem maiores chances de continuar sendo utilizados. Por outro lado, limitam o acesso a determinada parte da população, até mesmo a muitos torcedores que antes das reformas eram frequentadores de jogos, pois há um preço em espécie para se sustentar e finalizar tais transformações, fato que pode excluir ou segregar torcedores que em outros tempos podiam frequentar o estádio e ter momentos de lazer.

Drula (2015) ressalta que a primeira particularidade identificada para a elitização dos estádios é o preço elevado dos ingressos. "A rápida popularização dos jogos dos grandes clubes como atividade de lazer fez com que a venda de ingressos passasse a ser parte fundamental da 'saúde financeira' dessas agremiações" (SANTOS, 2012, p. 56), entretanto os altos preços impostos à população, apesar de serem parte importante da renda dos clubes de futebol, restringem a participação de certos indivíduos ao espetáculo.

Certeau (1995, p. 61-62) alerta sobre o perigo de criar duas classes de sujeitos em meio à sociedade. Nessa direção, haveria as pessoas que podem e as que não podem frequentar estádios.

A característica mais comum dos escritos que se tenta espalhar no momento e aos quais se dá a forma mais popular é dividir a sociedade em duas classes, os ricos e os pobres, representar os primeiros como tiranos, os segundos como vítimas, incitar à inveja e ao ódio uns contra os outros e preparar, desse modo, na nossa sociedade, que tanto se preocupa com a união e a fraternidade, todos os elementos de uma guerra civil.

Um dos entrevistados da pesquisa de Drula (2015, p. 92), ao ser questionado sobre a modernização do estádio, destacou a questão dos preços dos ingressos:

Tem um lado bom e ruim. Positivamente modernizou e evoluiu, e de outro lado elitizou, hoje o poder aquisitivo para obter um ingresso não contempla a todos, o que antigamente não ocorria, pois os preços dos ingressos eram baixos e acessíveis. A diferença é o povo que frequenta, de uma situação financeira melhor, eles não demonstram tanto sentimento ao clube (Frequentador 5).

Rodrigues (2016) entrevistou os frequentadores do entorno do Estádio Joaquim Américo e do Beira-Rio e constatou que, dos 55 participantes da pesquisa, apenas cinco alegaram que pretendiam ir ao estádio assistir a algum jogo da Copa do Mundo. Os demais afirmaram que 0 alto preço dos ingressos inviabilizaria a ida aos jogos.

Com a crise no Brasil, o poder de compra diminuiu, e houve consequentemente uma queda nos preços dos ingressos para o Campeonato Brasileiro, como, por exemplo, nos valores de ingressos para acesso ao Joaquim Américo. No Estádio Beira-Rio, porém, o valor do ingresso era superior ao da temporada anterior, no ano de 2015 (ESPN, 2016). Mas isso não significa dizer que os preços dos ingressos são acessíveis. 
Embora a pesquisa da ESPN aponte uma queda nos ingressos no pós-Copa, devido à crise no Brasil, um estudo realizado pela Pleuri Consultoria demonstra que o Campeonato Brasileiro é a competição nacional mais cara comparada às de outros países que têm uma forte cultura futebolística. A entrada mais barata no Brasil custa em média $\mathrm{R} \$ 51,74,0$ equivalente a US\$22, 62, um valor aproximado ao que se paga na França, onde os ingressos custam em torno de US\$25,35 (GLOBO ESPORTE, 2014).

Em uma entrevista, o professor Marcelo Proni, da Universidade Estadual de Campinas (UNICAMP), destaca que, comparando os preços dos ingressos no Brasil aos aplicados em países europeus, o valor aqui é mais barato. Contudo, o problema central é na renda per capita do Brasil, menor que a da Europa. Portanto, para Proni, a questão da elitização dos estádios está relacionada à distribuição de renda no Brasil (TORCEDORES.COM, 2016).

As novas formas que foram delimitadas para os estádios partem da concepção global, não havendo respeito pela cultura local, como aponta Santos (2006). Isso não significa dizer que é necessário negar a cultura global, instituída principalmente na lógica da Copa do Mundo. Mas é preciso respeitar a cultura local, a singularidade dos estádios, da torcida, daquela determinada comunidade.

Além da questão das cores dos estádios, internamente houve mudanças, como na forma de assistir aos jogos. 0 conforto e a proximidade ao gramado que os estádios passam a proporcionar são enfatizados, como uma tentativa de justificar o aumento dos preços dos ingressos, caracterizando uma exclusão sociocultural. Mesmo que os clubes criassem setores com diferentes preços, que em princípio atenderiam a todas as gradações sociais, o fato é que estariam fora do alcance de boa parte da torcida, em vista do aumento generalizado dos preços dos ingressos após a remodelação dos estádios (CRUZ, 2005, p. 87). E ainda,

o que chama atenção é a falta de manifestações contrárias a esse novo momento
de elitização dos estádios na imprensa esportiva. 0 aumento de custos e de conforto
parece justificar um aumento natural no preço dos ingressos. Mesmo que por um
momento ignoremos a majoração dos preços dos ingressos, a relação proposta
com esse novo modelo de praça esportiva parece restringir manifestações mais
populares ou de expressões de emoções coletivas (BANDEIRA; BECK, 2014, p. 10).

Já na época da Copa do Mundo, de acordo com Gaffney (2015), mesmo que o poder público tenha financiado a maior parte das obras dos estádios, a grande maioria dos brasileiros interessados em assistir aos jogos não teve essa oportunidade. Isso ocorreu por vários motivos. Para comprar o ingresso, era necessário um computador e acesso à internet; um cartão de crédito ou conta bancária, bem como possuir o valor integral do ingresso; habilidades de navegar em sites de compras e tempo disponível para acompanhar o sorteio, os preços e o limite disponível dos ingressos. Concordamos com Gaffney, pois, mesmo com o avanço da tecnologia, essas formas de adquirir o ingresso se tornaram limitadores consideráveis, visto que, no Brasil, tal acesso ainda é reduzido.

Como se pode verificar, a forma de comprar ingressos e 0 alto custo para a aquisição deles foram fatores limitantes à ida aos estádios nos jogos oficiais da Copa. Gaffney (2015, p. 199) ressalta que

[...] os mais pobres não têm mais chance de assistir jogos de futebol devido ao alto custo dos ingressos. Isso não quer dizer que eles não estejam presentes nos estádios. Estão ali trabalhando no campo ou nas arquibancadas, ou no beira do campo, ou depois de os holofotes apagarem, limpando o estádio. 
Para Bandeira e Beck (2014, p. 10),

[...] a Fifa destaca em suas exigências espaços reservados para os VIPs, mas ignora a necessidade de espaços populares, nem mesmo é possível permanecer em pé. 0 futuro parece dar aos estádios brasileiros um ambiente de teatro, de futebol europeu ou do conforto do sofá de casa.

Os autores Gaffney e Mascarenhas (2014, p. 10) apontam que "o alto preço dos ingressos para assistir aos 'novos espetáculos' funciona como um filtro, mais um mecanismo de exclusão social. $O$ ingresso se tornou um passaporte para adentrar um mundo de consumo, e o torcedor, um cliente". Para os autores, o Brasil comemora seus novos estádios como paradigmas da modernidade, mas tais paradigmas se localizam numa contramão da cultura popular.

Gaffney (2015) chama atenção que um dos problemas com o alto investimento dos estádios no padrão exigido pela FIFA será a questão de construir grandes estruturas, que consequentemente terão alto custo de manutenção. Ou seja, se a manutenção pode gerar mais custos, consequentemente os estádios necessitam de estratégias para arcar com essas despesas, seja nos preços dos ingressos, com eventos paralelos realizados nesses espaços, entre outras possibilidades.

Outra mudança destacada é a nova configuração na forma de torcer. 0 cenário dos novos estádios proporciona novas apropriações, novas maneiras de festejar. Os autores ainda apontam que "se as novas Arenas necessitarem de um público de teatro, existirá uma boa oportunidade para que os torcedores revolucionem as formas de assistir teatro no Brasil" (BANDEIRA; BECK, 2014, p. 10).

A vinda da Copa do Mundo para o Brasil trouxe consigo a necessidade de modernizar o espaço do futebol. De acordo com Ferreira (2014), até o termo "estádio" foi considerado um atraso, e passou portanto a ser denominado "arena" - a correta expressão da nova imagem que o Brasil queria propagar. $\mathrm{O}$ autor ressaltou que as mudanças:

[...] resultaram na criação de ambientes que, tecnicamente falando, atendiam a todas as exigências contidas no caderno de encargos da FIFA (limpos, claros, arejados e confortáveis). Entretanto, a modernização veio acompanhada de uma série de imposições e restrições que se adequam ao jeito europeu ou norteamericano de torcer, mas que pouco (ou nada) levaram em conta o nosso modo de apropriação desses equipamentos, construído ao longo de décadas (FERREIRA, 2014, p. 3).

A forma de torcer que a FIFA "estabelece" durante a Copa do Mundo se contrapõe com o modo de torcer constituído a partir de determinada cultura. Eduardo Galeano (2012, p. 14), em sua obra Futebol ao sol e à sombra, conta um pouco sobre como o torcedor se relacionava com o estádio não moderno.

Ondulam as bandeiras, soam as matracas, os foguetes, os tambores, chovem serpentinas e papel picado: a cidade desaparece, a rotina se esquece, só existe o templo. Neste espaço sagrado, a única religião que não têm ateus exibe suas divindades. Embora o torcedor possa contemplar o milagre, mais comodamente, na tela de sua televisão, prefere cumprir a peregrinação até o lugar onde possa ver em carne e osso seus anjos lutando em duelo contra os demônios da rodada.

Artefatos como bandeirões com mastros, sinalizadores, materiais da bateria de determinadas torcidas organizadas, entre outros itens icônicos do futebol não foram permitidos 
durante a Copa do Mundo e continuam proibidos após o mundial, fato que ocorreu no Estádio Joaquim Américo (DRULA, 2015). Essa nova forma de utilizar o estádio é aceita pelos clubes, pois os novos consumidores são mais comportados, não interferem no jogo, proporcionam mais dinheiro para as bilheterias e consomem os produtos no interior do estádio de forma passiva (GAFFNEY; MASCARENHAS, 2014).

Em relação à realidade brasileira sobre a identidade que os sujeitos têm com o estádio, é possível perceber que, historicamente, o clubismo é algo determinante. Capraro (2004) elenca que cores, tradição, hino e o próprio estádio são elementos cruciais para que a identidade clubística passe a ser a identidade dos torcedores de determinado clube. Assim, alterar qualquer componente dessa identidade sem um diálogo entre as partes pode romper elos culturais importantes.

Dessa maneira, a FIFA exigiu a remodelação dos estádios a partir de suas normas, que, segundo os documentos oficiais, ofertariam mais comodidade aos frequentadores. Entretanto, para torcedores que já frequentavam os estádios e tinham elos afetivos e um sentimento de pertencimento ao lugar, tais mudanças foram muito drásticas. Por exemplo, mudar as cores tradicionais do time e controlar as formas de torcer, entendidas como um código de identificação pode resultar em uma desapropriação desse espaço por quem tradicionalmente o frequentava.

Tais modificações estão atreladas ao novo olhar, à luz da globalização, que a sociedade tem do futebol. Os estádios não são mais grandes infraestruturas de concreto que abrigam partidas de futebol e meros torcedores aficionados, e sim palcos de um futebolespetáculo (PRONI, 1998), e o anfiteatro precisa estar à altura do show, tanto estética quanto financeiramente, mesmo que para isso a ética tenha que ser deixada de lado (HARVEY, 2012).

Evidencia-se assim que, mesmo tentando manter as tradições identitárias, "nem se cogitava que um clube de futebol trataria seus torcedores como 'clientes', trocaria de técnico pensando na cotação de suas ações na Bolsa ou procuraria diversificar suas áreas de investimento" (PRONI, 1998, p. 165), mas na era da globalização a questão de heterogeneidade e de mercadorias são aplicadas aos mais diferentes âmbitos da sociedade.

As características históricas que cultivavam um valor simbólico nos sujeitos que frequentavam os estádios antes de reformas específicas para as modificações em função da Copa do Mundo são deixadas de lado para Ihe serem atribuídos valores reais, de caráter financeiro, revelando que as transformações dos estádios de futebol estão voltadas muito mais para uma produção visando ao mundo globalizado do que para os sujeitos que possuam algum tipo de sentido e significado para com aquele espaço.

\section{CONSIDERAÇÕES FINAIS}

A reforma dos estádios, as (re)criações de suas estruturas, foram feitas de acordo com as normas da FIFA. As cores externas foram alteradas, passando a ser neutras (no caso, cinza), sendo esta uma das características das arenas esportivas da era moderna. Ou seja, é uma marca identitária da FIFA com seus respectivos estádios de futebol, um padrão encontrado em diversos países que já sediaram a Copa. Essas mudanças foram intensificadas tanto no Estádio Joaquim Américo Guimarães como no Beira-Rio. 
Tais transformações geraram, segundo dados desta pesquisa, uma série de mudanças nos códigos de identificação com o time e nas formas de torcer. Os novos assentos obrigam a torcida a permanecer sentada durante o jogo e restringe as torcidas organizadas de levarem seus instrumentos. 0 jogo passa a ser um espetáculo que exclui, visto que foram eliminados dos estádios os espaços populares para pessoas de baixa renda. $O$ torcedor passa a ser passivo, aquele que controla suas emoções e, principalmente, suas expressões corporais.

Nessa lógica imposta pela FIFA, para os estádios-sede da Copa do Mundo, com marca globalizada, o torcedor transformou-se em mero espectador; o ingresso, em cartão de crédito; a arquibancada, em plateia; o jogador, em popstar, o estádio, em teatro; a bandeira do time, em marca de empresas; a comida popular, em praça de alimentação; a cor vermelha, em cinza, portanto "neutra", sem identidade. Ao torcedor coube se adaptar às novas formas de frequentar os estádios. Nesse caso, a cultura global acabou interferindo na cultura local, ou seja, o conhecido "vermelho do caldeirão" passou a ser a arena multifuncional do famoso neutro "padrão FIFA".

O ideal seria que os espaços (re)construídos respeitassem aspectos da memória coletiva dos sujeitos frequentadores dos estádios, no intuito de manter a identidade com a cultura local dos citadinos. Nesse sentido, a conexão entre o local e o global deve ser estabelecida de forma mais equilibrada, para que não haja segregação, mas sim maior apropriação dos cidadãos em espaços e equipamentos de esporte e lazer nas cidades.

\section{REFERÊNCIAS}

ALVES, Vânia de Fátima Noronha. Verbete: Cultura. In: GOMES, Christianne Luce. Dicionário crítico do lazer. Belo Horizonte: Autêntica, 2004. p. 54-59.

ANIBAL, Alexandre Leon. Nova Copa Roca, novas sedes. 1․ jul. 2011. Disponível em: <http://www. futebolportenho.com.br/2011/01/07/nova-copa-roca-novas-sedes/>. Acesso em: 8 jul. 2017.

ARAÚJO, Ricardo. Arenas esportivas: do conceito básico ao estado da arte. In: DACOSTA, Lamartine et al. (Org.). Legados de megaeventos esportivos. Brasília: Ministério do Esporte, 2008. p. 553-555.

BANDEIRA, Gustavo Andrada; BECK, Matheus Passos. As novas arenas e as emoções dos torcedores dos velhos estádios. Esporte e Sociedade, v. 9, n. 23, p. 1-13, 2014.

BERZAGUI, César. As arenas esportivas em Porto Alegre: modificações nos espaços do torcedor a partir da Copa do Mundo. 2014. 61 f. Trabalho de Conclusão de Curso (Bacharelado em Geografia) Universidade Federal do Rio Grande do Sul, Porto Alegre, 2014.

BRASIL. Conselho Nacional de Saúde. Resolução 466/12. Brasília, DF, 2012a. Disponível em: $<$ http://bvsms.saude.gov.br/bvs/saudelegis/cns/2013/res0466 1212 2012.html >. Acesso em: 25 jun. 2015.

BRASIL. Ministério do Esporte. $4^{\circ}$. Balanço de ações para a Copa (1ํㅡㄹ Ciclo). Cidade-Sede de Curitiba, 2012b. Disponível em: <http://www.copa2014.gov.br/sites/default/files/publicas/12272012 balanco curitiba.pdf>. Acesso em: 10 jul. 2017. 
BRASIL. Portal da transparência. Copa 2014. Reforma do Estádio Beira-Rio. 2014. Disponível em: $<$ http://www.portaltransparencia.gov.br/copa2014/cidades/execucao.seam?empreendimento=147>. Acesso em: 5 jun. 2017.

BRANSKI, Regina Meyer et al. Infraestruturas nas Copas do Mundo da Alemanha, África do Sul e Brasil. Cadernos Metrópoles, v. 15, n. 30, p. 557-582, 2013.

CAMPOS, Priscila Augusta Ferreira; AMARAL, Silvia Cristina Franco. A Copa do Mundo de Futebol de 2014 e o (novo) Mineirão. Revista RUA, v. 1, n. 19, p. 40-55. 2013.

CAPRARO, André Mendes. O Estádio Joaquim Américo: a "Arena da Baixada" e a identidade clubística do torcedor do Clube Atlético Paranaense. CAMPOS - Revista de Antropologia Social, v. 5, n. 1, p. 131-149, 2004.

CERETO, Marcos Paulo. Arquitetura de massa: o caso dos estádios brasileiros. 2003. 311 f. 2003. Dissertação (Mestrado em Arquitetura) - Programa de Pesquisa e Pós-Graduação em Arquitetura PROPAR, Universidade Federal do Rio Grande do Sul, Porto Alegre, 2003.

CERTEAU, Michel de. A cultura no plural. Tradução Enid Abreu Dobránszky. Campinas, SP: Papirus, 1995.

CRUZ, Antonio Holzmeister Oswaldo. A nova economia do futebol: uma análise do processo de modernização de alguns estádios brasileiros. 2005. 124 f. Dissertação (Mestrado em Antropologia Social) - Museu Nacional, Universidade Federal do Rio de Janeiro, Rio de Janeiro, 2005.

DRULA, Andréia Juliane. 0 processo de transformação de um estádio para arena: caso "Arena da Baixada". 2015. 130 f. Dissertação (Mestrado em Educação Física) - Setor de Ciências Biológicas, Universidade Federal do Paraná, Curitiba, 2015.

ESPN. A crise chegou? Preço médio do ingresso no Campeonato Brasileiro despenca. 30 maio 2016. Disponível em: <http://espn.uol.com.br/noticia/602762_a-crise-chegou-preco-medio-doingresso-no-campeonato-brasileiro-despenca>. Acesso em: 5 jun. 2017.

FERREIRA, Fernando da Costa. O novo Maracanã como arena do embate entre diferentes formas de torcer: uma contribuição da Geografia dos Esportes. Revista geo-paisagem, v. 13, n. 26, p.1, jul./dez. 2014.

FIFA. Estádios de futebol: recomendações e requisitos técnicos. 5. ed. Zurich, Suíça: FIFA, 2011. Disponível em: <http://img.fifa.com/mm/document/tournament/competition/01/37/17/76/p sb2010 stadiumbook ganz.pdf>. Acesso em: 5 jun. 2017.

GAFFNEY, Christopher. Arenas de conflito: os processos conflituosos durante a preparação para a Copa do Mundo no Brasil. In: SANTOS JUNIOR, Orlando Alves dos et al. Brasil: os impactos da Copa do Mundo 2014 e das Olimpíadas 2016. Rio de Janeiro: Observatório das Metrópoles, 2015. p. 185-202.

GAFFNEY, Christopher; MASCARENHAS, Gilmar. A festa acabou? Está só começando? Os novos estádios de futebol e a disciplina socioespacial. In: HOLLANDA, Bernardo Borges Buarque de; BURLAMAQUI, Luiz Guilherme (Org.). Desvendando o jogo: nova luz sobre o futebol. Rio de Janeiro: EDUFF, 2014.p. 85-106.

GALEANO, Eduardo. Futebol ao sol e à sombra. Porto Alegre: L\&PM, 2012.

GASTAL, Delene de Souza. Clubes, estádios e torcidas: a elite e o "povão" na história do Sport Club Internacional. 2009. 51 f. Trabalho de Conclusão de Curso (Graduação em História) - Instituto de Filosofia e Ciências Humanas, Universidade Federal do Rio Grande do Sul, Porto Alegre, 2009. 
GLOBO ESPORTE. Campeonato Brasileiro tem o ingresso mais caro do mundo. 13 ago. 2014. Disponível em: <http://globoesporte.globo.com/futebol/noticia/2014/08/campeonato-brasileiro-tem-0ingresso-mais-caro-do-mundo-aponta-estudo.html>. Acesso em: 10 jul. 2017.

GUICHARD, Diego. Fotos: à espera da festa, veja Beira-Rio em todos os detalhes. Fotografia de reportagem. Globo, 19 mar. 2014. Disponível em: <http://globoesporte.globo.com/rs/futebol/times/ internacional/fotos/2014/03/fotos-espera-da-festa-veja-beira-rio-em-todos-os-detalhes.html>. Acesso em: 8 jul. 2017.

HARVEY, David. Condição pós-moderna. São Paulo: Loyola, 2012.

MARCONI, Marina de Andrade; LAKATOS, Eva Maria. Técnicas de pesquisa. São Paulo: Atlas, 2011.

PRONI, Marcelo Weishaupt. Esporte-espetáculo e futebol-empresa. 1998. 275 f. Tese (Doutorado em Educação Física) - Faculdade de Educação Física, Universidade Estadual de Campinas, Campinas-SP, 1998.

RECHIA, Simone; SILVA, Emília Amélia Pinto Costa. Espaços e equipamento de lazer em época de megaeventos esportivos: entre o sonho mais dourado e a realidade mais cruel. In: MARCELLINO, Nelson Carvalho (Org.). Legados de Megaeventos Esportivos. Campinas: Papirus, 2014.p. 197-220.

RODRIGUES, Emília Amélia Pinto Costa. Os espaços das cidades e os megaeventos esportivos: uma análise da Copa do Mundo de Futebol 2014 na Região Sul do Brasil. 2016. 201 f. Tese (Doutorado em Educação Física) - Departamento de Educação Física, Universidade Federal do Paraná, Curitiba, 2016.

SANTOS, Milton. A natureza do espaço: técnica e tempo, razão e emoção. 4. ed. São Paulo: Edusp, 2006.

SANTOS, João Manuel Casquinha Malaia. Torcer, torcedores, torcedoras, torcida (bras.): 1910-1950. In: HOLLANDA, Bernardo Borges Buarque et al. A torcida brasileira. Rio de Janeiro: 7 Letras, 2012. p. 51-84.

TORCEDORES.COM. Por que os ingressos de jogos de futebol são tão caros? 27 out. 2016. Disponível em: <http://torcedores.uol.com.br/noticias/2016/10/por-que-os-ingressos-de-jogos-defutebol-sao-tao-caros >. Acesso em: 10 jul. 2017. 